Coaches as sport workers: Professional agency within the employment context of elite European basketball

\author{
Laura G. Purdy \\ Department of Sport and Physical Activity \\ Edge Hill University \\ St Helens Road, Ormskirk, L39 4QP, UK \\ purdyl@edgehill.ac.uk
}

Geoffery Z. Kohe

Institute of Sport and Exercise Science

University of Worcester

Henwick Grove, Worcester, WR2 6AJ

g.kohe@worc.ac.uk

\title{
Rūtenis Paulauskas
}

Lithuanian University of Educational Sciences

Studentų g. 39, Vilnius 08106, Lithuania

and

Lithuania Sports University

Sporto g. 6, Kaunas 44221, Lithuania

rutenis.paulauskas@leu.lt 


\begin{abstract}
Increased activity of multiple stakeholders (e.g., agents and owners) have created new challenges for some coaches working in professional sports clubs. The purpose of this project was to draw attention to the normative or accepted practices inherent in sport work, some of the day-to-day realities of some coaches working in this context, and to understand how coaches' perceptions of other stakeholders come to bear on their individual circumstances, career expectations/objectives and professional agency. Data were generated from semistructured interviews with seven professional basketball coaches who worked in top-level European clubs. The analysis reveals the coach’s relationships between some owners and agents differed with respect to exercising professional agency, and, coach’s decisions and actions were tied to their professional ideals as well as understandings of what they need to undertake their work effectively and negotiation and/or adjustment strategies. Occasionally coach's work practices could be viewed as antithetical to employment security, however, the presence of insecurity was at times embraced and used strategically to affect workers' career decisions. Amid contemporary regional geo-political shifts, this work aids examinations of global sport settings, structures and issues that may contour sporting professionals' lives.
\end{abstract}

Key words: sports coaches, professional agency, sport work, elite basketball, European context 


\section{Introduction}

Sport and coaching literature has increasingly focussed on the social, cultural and political forces influencing coaches’ employment environments, careers and working practices (e.g., Christensen, 2013; Lavallee, 2006; Purdy \& Potrac, 2014; Thompson, Potrac \& Jones, 2015). Substantial consideration within this research has been afforded to conceptualisation of the varied role(s) of the coach and their 'effectiveness' in their careers and specific employment contexts (e.g. Mills \& Denison, 2016; Santos, Jones \& Mesquita, 2013). Reflecting the disciplinary genesis in education, sociology, psychology and management, much of the work within the coaching field has relied upon social theories and philosophical constructs and frameworks within these areas to help understand and analyse the complexities of coaches' experiences and the issues that arise from the execution of their specific roles (e.g. Cushion \& Jones, 2006; Jones, Armour \& Potrac, 2004; Jones \& Wallace, 2006; Purdy \& Jones, 2011). In this regard, contemporary work has utilised notions of micropolitics and orchestration to problematize the ways in which coaches ply their trade and, importantly, negotiate their 'selves' and social interaction within given settings (Potrac \& Jones, 2009; Thompson, et al. 2015).

The aforementioned scholarship has advanced appreciations of the social and political forces contouring coaches' work and has led to usefully positioning coaches and their careers as political and politicized. Such repositioning necessitates new theoretical and disciplinary insight. To this end, and starting from the premise of recognising and respecting coaching as serious work, we draw on the sociologies of work and labour to frame coaches as sports workers (e.g., Markovits, Boer \& van Dick, 2014; Galgóczi, Leschke \& Watt, 2016). In doing so, we contextualise coaches' labour as entrenched within the organisational processes, bureaucracy, political machinations, marketplace imperatives and performance operations of an increasingly competitive and dynamic sport industry. 
Within the sociology of work, although some attention has been directed toward athletes (Roderick, 2006; 2013), the diverse forms of sport employment within the performance setting have not been afforded due consideration. In particular, there has been a paucity of discussion around the work of coaches as professionals, and the ways in which coaches' work have been developed and positioned within the sports industry. This neglect has been underscored by a prevailing romanticism within popular discourse and literature that has venerated sport spaces, athletes, and by default coaching, as unique, special and sacred (Cooper, 2010). Such assumptions may have derived from the notion that coaching in some cultures has been considered an amateur occupation aligned to a nostalgia for the sport, its constituents and culture (Strachan, 2013).

Akin to other forms of employment, the performance coaching role is characterised by a set of expectations, obligations and demands (e.g., administration, stakeholder engagement, accountability and surveillance mechanisms) that extend beyond the immediate focus on performance practicalities. While such activities may be contiguous with non-sport employment, they present an imposition that often jars with coaches' conceptualisations of their roles and their understanding of the realities of their work (Cooper, 2010). Herein lies one of the issues with the portrayal of coaches' work; essentially, that such tensions over the seriousness of the work versus 'the job as past time' may led to a rejection and abdication of responsibility for aspects that some coaches deem peripheral, inconsequential, or not in keeping with their personal understandings of their roles.

In response to this evolution of sports employment, there has been increased activity of players' unions, athletes' and coaches' commissions and entities like the Court of Arbitration for Sport to improve democracy, representation and advocacy opportunities for sport workers (EU Athletes, 2015; Rigozzi, 2010; Syndex, 2013). Irrespective of these mechanisms, their place in sport deserves further scrutiny. Within the dynamic and diverse 
European context, the influence of multiple stakeholders (e.g., agents, sponsors, owners), have created challenges for sport organisations and those who negotiate and represent sport workers' needs and interests (Syndex, 2013). For at least 28 of the countries in Europe, EU agendas, characterised by regulation, regional parity, collective responsibility, codependency, the desire for greater transparency, and increased representative opportunities, are defining the landscape in which sport organisations operate (Henry, 2013; Chatzigianni, 2014). Yet, irrespective of moves toward continental synergies there remains varied strategies and responses to the development of equitable and representative sports policies and workers’ rights therein (Chatzigianni, 2014).

Notwithstanding international and domestic efforts made in response to EU developments, multi-level/multi-sport European entities have been established to advocate for sport worker's rights (e.g. coaches' associations from various countries). These organisations have, invariably, been instrumental to allegedly improving the employment environments for sport workers; however, they are also symbolic and symptomatic of how the sports industry has become marketised and increasingly crowded with an array of stakeholders who have diverse interests, investments and agendas (Schulenkorf \& Frawley, 2016). In some cases, the 'noise’ of this mélange of sport workers has impacted upon coaches' considerations of their work spaces; and the abilities or restrictions upon coaches in terms of the active and/or passive ways they negotiate their roles (which is framed in the following section as professional agency). Therefore, the purpose of this project was to draw attention to the normative or accepted practices inherent in sport work, some of the day-today realities of some coaches working in this context, and to understand how coaches' perceptions of other stakeholders come to bear on their individual circumstances, career expectations/objectives and professional agency. 


\section{Theoretical Framework}

Coaches occupy central roles within their employment contexts. They undertake leadership positions within the working environment, assume considerable responsibilities for the team's welfare, performance and strategic direction, act as a conduit between other employees (e.g. players and support staff) and management, and, in some cases, take key positions in interactions with external stakeholders. Akin to many other forms of employment, coach’s work and working conditions can also be marked by turbulence, uncertainty and change, and as such, a coach must negotiate the realities of their daily occupations in conjunction with their longer-term career aspirations. While a coach's work may be considered integral to the management and sustainability of the 'business' of the sport, they are not unlike other sorts of sports workers whose day-to-day professions are also shaped by their personal career histories, emotional affiliations to the profession, sociocultural contexts, immediate social interactions, and future employment trajectories (Morrow \& Howieson, 2014). Accordingly, the particular context in which coaches operate (in this case, the professional European basketball setting) affords a useful space to better understand the sport industry and coaching profession and the socio-cultural, political and economic constraints that influence individuals’ career choices.

Aspects of the sociology of work, and a particular notion of agency, is useful here in articulating a key aspect of coaches' work settings; namely, the influence of, and interactions with, owners, agents and other stakeholders. These relationships extend beyond the immediate performance-orientated operations of the sport and form part of the wider, intricate, and layered social and political network that coaches must navigate and contend with as part of 'the job'. Sociology of work debates aid a closer analysis of particular organisational relationships that have come to bear on this set of sport workers. Of particular relevance here are studies that have interrogated global, regional and local employment 
inequities and discontent, articulated the intended and unintended consequences of diversifying/diversified labour markets, challenged the utility of representational mechanisms, and advanced appreciation for new work spaces (Markovits, Boer \& van Dick, 2014; Galgóczi, et al., 2016). Such work is of value in problematising the sport industry as a labour space and the varied nature of its constituents' employment as fraught with economic, political, socio-cultural and ethical concern (Wallace, 1988; Roderick, 2006; 2014); and, thus, worthy of consideration and critique. Adopting this particular employment context and theoretical focus highlights the importance, nature, extent of the coaching profession and adds weight to the complexities of this distinct working environment. Additionally, the disciplinary lens we employ enables us to position coaches’ working relationships, actions and behaviours not merely as individualised (which, we respect, they might well be), but rather situate these sport workers within part of a wider, dynamic, and ever changing industry landscape (in this case one characterised by global sport capitalism, intra-national and regional attempts at regulation and stability, and localised socio-political idiosyncrasies). The attention on professional agency, employed in the effort to understand some of the how and why of coaches' action/inactions, more specifically, also enables us to fortify the debate about some of those who work in this corner of the coaching profession.

Congruent with our interdisciplinary intentions to build on academic considerations of sport workers, the theoretical cues that frame this work are predominantly taken from scholarship on professionals within educational settings. Research has positioned workers’ agency and actions in this context as strategic and revealed that workers make conscious choices regarding how to act and when they want to act (Mrozowicki, Pulignano \& Van Hootegem, 2010; Vähäsantanen, 2015; Vähäsantanen \& Eteläpelto 2015). Here professional agency can be understood as the individual's opportunities to influence his or her own work (Ketelaar, Beijaard \& Den Brok, 2012; Priestley et al., 2012). This scholarship also draws 
attention to the socio-cultural and political specificities of workers' employment conditions. In harmony with our explanation of coaches' work above, central to our conceptualisation of professional agency was Vähäsantanen \& Eteläpelto’s (2015) and Collin, Paloniemi and Vähäsantanen’s (2015) emphasis on the relationship between workers, their individual histories, unique context and future prospects. For these scholars, professional agency is not a static, unchangeable, personal attribute to be acquired, but rather a social and political process that individuals employ in relation to work-related issue and, moreover, undertake decision making and position-taking effecting their professional work and/or identity (Eteläpelto, Vähäsantanen, Hökkä \& Paloniemi, 2013). Here, for instance, we might consider how teachers might react to calls for industrial action which might be complicated by their professional and ethical ideal and immediate working relations. Or, in relation to sport workers, for example, the choices made when there is economic uncertainty or management interference that necessitate individuals contemplate their immediate and longer term job security and the sustainability of their roles within the club.

Integral in Vähäsantanen and Eteläpelto’s (2015) theorising, and implied in the anecdotal examples above, is the necessity of acknowledging the wider milieu in which individuals work and also recognising that an individual's capacity to enact professional agency is contingent upon the associated socio-cultural constraints and resources they have at their disposable (in the case of our coaches, for example, their professional credibility, social networks, economic and political capital, and/or sporting habitus). To simplify, how coaches have become professionals, who they are and are connected to, their employment genealogy, performance record, professional integrity, social connections and organisational relationships, understanding of how to do their job 'effectively', and their personal perception of themselves and longevity in the role and sport, all may come to bear on their work-related decision making capacities. In Vähäsantanen and Eteläpelto (2009) and 
Eteläpelto et al.’s (2015) work, for instance, teachers’ practices of professional agency were enmeshed within their sense of self (within the immediate job and wider career), their sense of professional and ethical obligations, duties, interests and objectives. Yet, to reiterate the importance of relationships within professional agency, teachers' capacities for agency were intricately bound to their history and the immediate work setting and also the social aspects of their work (Lipponen \& Kumpulainen, 2011). As Vähäsantanen and Eteläpelto (2009) and Eteläpelto et al. (2015) noted, for some teachers the nature, extent, and political ramifications of these relationships also, ultimately, came to bear on the ways in which professional agency was manifest in particular situations. For these scholars (i.e. Vähäsantanen \& Eteläpelto, 2009; Lipponen \&Kumpulainen, 2011), professional agency is of value because it highlights how teachers navigate their work setting, but also provides a framework to analyse and evaluate the instances and ways it might be utilised where teachers feel their professional ideals and identity are threatened, and/or their ethical values compromised. Moreover, it also attends to how, when and why particular employees may choose to act when there is a sense of diminished autonomy within their work (Pyhalto, Pietarinen \& Soni, 2014). For example, teachers exerted more professional agency in daily classroom management practices but less agency within the wider managerial and social contexts they inhabited where there was perceived to be invariably more organisational constraints, greater potential consequences and risk, and less power and capacity for action that might initiate change within the working environment. For coaches, it is worth considering how this correlates to their day-to-day work and effectiveness in their immediate performance environment and the difficulties that may be confronted with in addressing wider organisational, managerial or employment issues within their job where there are competing interests, invariably more tiers to the political hierarchy, and potentially more stakeholders involved, and higher stakes at play. 
The recent interest in professional agency (in the educational setting) as a means to interrogate workers’ capacities to determine their own work choices, experiences, opportunities and identities may not seem nouveau; indeed, issues of agency (and the implied power relations therein) have been evident within labour scholarship for some time (Willis, 1977; Glavin, 2013). Despite the emergent scholarship, the concept of professional agency may, invariably, still be considered to be underdeveloped. There is, for instance, a paucity of discussion around the consequences that might accrue for individuals who are limited in exerting their agency, the exact processes individuals undertake when deciding upon course of action regarding professional agency, what professional agency 'looks’ like in varied industry settings, the role(s) organisational settings play in enabling or constraining particular forms of professional agency, and whether the ebb and flow of professional agency across an individual's career span has wider implications that extend beyond their work identity. These lacunae notwithstanding, the work we draw upon from education goes someway to enabling us to understand how and why some workers behave and (inter)act within certain industry settings. In a similar manner, the utilisation of professional agency within a sporting context helps generate a new space to consider some of the ways sport workers ply their trade.

The theoretical crux of professional agency is that it necessitates the development of a more nuanced understanding of the individual worker first and foremost. What follows, to employ the theoretical imperatives of professional agency and advocacy politics and agendas inherent within the sociology work domain (Gardiner, Stuart, MacKenzie, Forde, Greenwood \& Perrett, 2009; Mrozowicki et al., 2010; Berntsen, 2016), is then an acknowledgement that workers’ capacity/incapacities for action are situationally specific, historically informed, politically motivated and socio-culturally contoured, and, can be operationalised to improve working conditions. From this, it is then possible critically examine and articulate how individual's predispositions, current contexts, and future concerns manifest themselves in 
their work, the dynamics of the daily working relationships, the choices they make with regards to occupational issues, and how they choose to navigate wider organisational influences and stakeholder's interactions to better their circumstances. In placing the emphasis on the individual capacities and intentions of the work, professional agency is also useful in challenging assumptions about collective advocacy mechanisms (e.g. those such as collective bargaining, player unions, athlete commissions etc. that are based on sport workers having consistent shared goals, values, outcomes). While not denying such mechanisms serve a purpose (e.g., helping improve conditions for players), this framework crystalises the necessity of appreciating how individual workers configure their own identities, roles and experiences for themselves. This work specifically recognises the contextual frameworks in which sports workers operate and orchestrate the career decisions and trajectories accordingly. In doing so, we also problematise the existent victim narrative in the literature (e.g. Roderick, 2006; 2014) which portrays sport workers as docile, compliant or possess little, limited or no agency. they operate and orchestrate the career decisions and trajectories accordingly.

This emphasis on professional agency also underscores how varied and fluid its deployment and use is by individuals within their careers and across employment settings. As Engle and Faux (2006) and Rainio (2008) suggest, professional agency can manifest itself in ways the empower individuals, challenge the status quo, disrupt conventional power relations and provide opportunities for representation, participation and voice. Yet, professional agency can also be employed to varying degrees (or more passively as we explore further on), and may also be highly contingent upon worker's backgrounds, personal persuasion and employment setting (Lasky 2005; Engeström \& Sannino 2010; Stronach et al. 2002). Professional agency may help explain, to a point, the ways some professionals approach their work and career choices; the varied responses to organisational and stakeholder influence in 
their daily practices and spaces; the resignation, indifference or deference some coaches may experience with regards to careers and/or immediate employment; the relative importance or insignificance of historical connections or social connections in shaping professional ideals and decisions; and, their approach to the political realities of the job and they strategies to sustain or change their position during career navigations. In the theoretical sense, the value in this paper lies within opening a new employment space in which to examine the sociology of work relations via the daily realities of individual sport workers. The paper thus contributes toward a greater recognition within labour and industrial relation scholarship of the experiences of individuals in particular organisational settings.

\section{Methodology}

Grounded in the interpretive paradigm, this work comprised of an intrinsic case study (Stake, 1995) to derive an understanding of the career experiences of professional basketball coaches in Europe. With its own unique history, the case is a complex entity influenced by a number of contexts: physical, economic, ethical, aesthetic, etc. (Stake, 1995). Seeking to discover what is common and unusual within a particular setting, the value of such an approach is to enable readers to vicariously experience the lives of others and draw comparisons with familiar situations and contexts (Stake, 1995). Whilst there is ongoing debate whether a case study is a methodology or/and method (Thomas, 2010; Miles, 2015), in this work, case study is understood as a methodology which aims to be "particularistic, descriptive and heuristic” (Merriam, 2009, p. 46).

Notwithstanding a cursory overview of the European employment sector from a managerial perspective (Madella, 2003), particular concern within the literature has developed with regards to the evolution of sport employment within Europe and the increased labour regulation in the sector (Henry, 2013; Syndex, 2013). In addition, the European setting 
is of interest as the economic crisis of the past decade has increased the precarity of work in this sector (Markovits et al., 2014).

Significant attention has been afforded to football (as the predominant sport on the continent), and within this space to the key issues of labour migrations, statutory controls over sport industry practices, and the application of employee legislation (Parrish, 2016). In contrast, basketball also has an established history in Europe, however it has not received similar attention. Regardless of basketball's scope, the sport still affords scholars an interesting space in which to explore the lives and careers of sports workers. For example, within this context, professional coaches stitch together 'patchwork careers' (Fevre, 2007) of short-term work which are characterised by fixed-term contracts, involuntary job loss, (brief) spells of unemployment, and movement to and from lower leagues. Therefore, this paper focuses on the career experiences of professional basketball coaches in Europe.

\section{Sampling and method}

Purposeful sampling was used (Patton, 1990). Initially, a criterion-based sampling approach was employed as participants were selected as a result of their positions with toplevel basketball teams in Europe. Coaches were recruited by two gatekeepers who informed the potential participants of the study and asked if they would consider participating. Initially, participation was limited to coaches who were confident in undertaking an interview in English. Participants were given information sheets and informed consent forms (in their preferred language) to ensure they understood the aim and requirements of participation.

The coaches were working with teams in the top-tier of European competitions or in the process of seeking new contracts. The participants ranged in age from 40-65 and are referred to by pseudonyms as Coaches A-G. Of the seven participating coaches, two were in the early stages of their professional careers, having recently retired from playing 
professionally whilst the other coaches had a minimum of 15 years of experience (as head and/or assistant coaches) in European clubs. Four of the coaches were former professional basketball players who, upon retiring from playing at highest level in Europe, moved into coaching. However, three of the coaches did not play at highest level, rather, they 'fell' into coaching as opportunities emerged. All participants commented on their love of the game which, either kept them involved (as former players) or motivated them to pursue careers as coaches. With the exception of one coach, who, in initial stages of career was also a journalist who moved into full-time coaching role, all others were full-time, paid professional coaches.

Data were generated via semi-structured one-to-one interviews. The interviews ranged in duration from 45 to 120 minutes and centred on the career experiences; the highlights and low points and the meaning of these to the participant and his career trajectory. Semi-structured in nature, the interviews possessed the flexibility to explore topics that arose in the conversation (Freebody, 2004). The interviews were recorded via a Dictaphone and transcripts were returned to the interviewee to edit (Emerson, 2001).

\section{Analysis}

An iterative analysis was undertaken. Informed by Tracy (2013), such an approach allowed for interchanges between emic readings of the data and a reflexive, etic use of the literature. The analysis commenced with an immersion in the data by reading and re-reading the transcripts. Data were coded according to meaningful words and phrases. Such codes related to experiences and meanings regarding what it meant to be a professional coach and the subsequent highlights and challenges. Following the initial coding, discussions with coauthors about the data and engagement with the literature aided in further sense making and a deeper reading of the data. As such, the transcripts were re-read and new codes assigned. Codes were then compared across transcripts and organised into wider themes such as: 
'interference', 'ethical concerns', 'self-preservation'. These themes were then reviewed in light of work on professional agency (e.g. Pyhalto et al., 2014; Eteläpelto, Vähäsantanen \& Hökkä, 2015). In the following section, the data are organised according to the following themes: owners and agents.

\section{Results/Discussion}

Congruent with the literature above, the story unfolding in this paper is one of sports workers being considerably influenced a range of stakeholders, and the implications that this influence has on the realities of the job and individual's 'effectiveness' in their roles and their ethical orientations. Moreover, what we begin to read in these sports workers' experiences is a recognition of the fragility of their position and employment context and a strategic acknowledgement that entrenched uncertainties of the workplace may be navigated. While it may be possible to understand sports workers’ practices and approaches in this regard in micro-political terms (Blase, 1991; Hoyle 1982) or impression management (e.g. Goffman, 1959), here the point of the following narrative is to articulate features of the broader labour context and structural forces that lay beyond the level of inter/intra-personal interactions in situ.

Professional agency: Owners. Professional coaching in this context is characterised by the necessity of consistently winning, with the imperative that winning correlates to improved funding opportunities. As such, there are significant commercial implications for poor performance. However, the contextual economic undertones of coaches' employment, at least here with regards to the owner's hand in coaches’ work, have consequences for their professional agency.

I think the last ten years maybe? It's a strange situation. Some owners, they start to care about the games more than coaches...They want to make decisions inside of the 
team. I don’t agree with this, I decide who will play and who will not play and for how many minutes... [If owners get too involved], you cannot work normally (Coach F).

The situation articulated by this coach coheres, within the framework of professional agency, with workers' abilities to recognise the definition of their role within their immediate employment context and acknowledge the broader complexity of forces acting upon their labour spaces. Rehearsing the notion of the social inherent in the conceptualisation of professional agency, the interactions, relationships and interdependencies between owners and coaches can create a challenging work space. Previous work (e.g. Potrac \& Jones, 2009) has drawn attention to the complexities of coaches' relationships with stakeholders (e.g. athletes, other coaches, managers, or owners), with particular emphasis placed upon how coaches manage and negotiate constraining influences. However, for these professional basketball coaches, it appears while some ‘interference’ from stakeholders (i.e. owners) is expected, there were limits to what the coaches were willing to accept in the immediate employment and further over the course of their professional careers. What was evident was that coaches were also frequently being confronted with the necessity of dealing with owners who, although naturally being in a position of power, exerted an increasing amount of control over coaches and their practices.

Sometimes you deal with people who don't know the sport and people around them tell them things and then they put pressure on the coach... Somebody who has not played basketball might have big money. You might talk to him and try to explain it but he cannot understand, it's a very difficult situation (Coach F).

We have a president who liked a player. Because he liked the big star, he wanted to recruit him... and he told me 'You must to win with this player, because he's a big 
star'. But the player didn't practice, he didn’t sleep, he didn't play well and he didn't score! (Coach G).

As the coaches noted, with increasing owner interference 'you cannot work 'normally' and ‘it’s a very difficult situation'. Such sentiments were largely founded in their conceptualisations of what was and what was not 'normal' in these particular environments. In this case, the coaches recognised the pronounced influence of stakeholder intervention and owner meddling which was incongruent with their previous concepts of coaching. This led to the belief that they could not function effectively (interpreted as unrealistic job expectations by the coaches as to the everyday nature of the job re: micropolitics). Invariably, the coaches' perceptions of such situations had implications with regards to overall job satisfaction, motivation, professional identity, and sense of stability in the role and day-to-day working relationships. For example, the over involvement of owners resulted in coaches 'reading' the situation and deciding what was not 'workable'. This involved considering their expectations and professional ideals. Such reflection resulted in a 'reconfiguring' of their professional ideals in an effort to salvage some job satisfaction (i.e. adjusting to the owner's demands and accommodating their input). In contrast, coherent with Vähäsantanen et al. (2015), the coaches interviewed chose to be more active in their assertion of agency; namely, by ending their contractual obligations on mutual terms as opposed to poor performance or the owner's dissatisfaction. This enabled the coaches to strategically manoeuvre their way out of difficult situations, whilst concomitantly retaining credibility and their professional reputation and integrity. In addition, they subsequently negotiated shorter contracts which, they believed, were more realistic in terms of the prevailing employment conditions. The motivation for such a strategy was to protect their reputation (and professional ideals) which was their currency for further employment. As Coach A stated, "I left... it was only time before [the 
owner] would cut me, so I left... because my reputation is important, and I don't want to kill my name so it was better for me to leave.”

In addition to the importance of the coach's name with regards to teams' performances, the coaches also commented on the importance of their reputation, specifically, their professional ideals. Here we recognise that coach's approaches may be read in terms impression management (e.g. Goffman, 1959; Jones, Armour \& Potrac, 2004; Chesterfield, Potrac \& Jones, 2010; Ronglan \& Aggerholm, 2014). However, the intention here is focus more on the issues of agency, labour, and the coaches' navigations within the wider employment context. As Coach E commented, "I am one of the coaches who was never contacted by an agent or a club that is known to do something illegal... They don't like me because I am a clean coach.” Building on work by Wallace (1988) and Roderick (2006; 2014) who stress that coaches’ decision making capabilities and the invariable actions are fraught with ethical dilemmas, based on the aforementioned data, these are also applicable to coaches’ career decisions.

Demonstrating varying degrees of success, it is evident that coaches are endeavouring to achieve their career plans by accepting to renegotiate or deciding their situation is untenable and terminating their contract (to be discussed later). This could be viewed as a temporal point at which professional ideals collide, intertwine with and crystallise with the immediate contextual conditions, historical and broader socio-cultural influences, future career aspirations and coach’s underpinning ethical concerns and values. The reading of coach’s lives here is contiguous with wider industrial relation and sociology of work examinations (e.g, Gardiner et al., 2009; Lipponen \& Kumpulainen, 2011), that have critiqued professional agency and sought to demonstrate the ways in which worker's actions and behaviours are contingent, at least to a significant degree, on the unique (sub)cultural milieu, personal histories and employment context. To recall Vähäsantanen (2015) and 
Vähäsantanen and Eteläpelto’s (2015) framing of professional agency, an appreciation of the contexts in which coaches operate is fundamental. Of particular importance is the necessity of understanding how the historical, socio-cultural and political specificities of their employment conditions shape their conceptualisation of the self, their role and their immediate career decisions. To recall the scholarship rehearsed at the outset of this paper on the contextualisation and conceptualisation of the coach and their work, an appreciation the sub-cultural (employment) milieu, and the related attentiveness afforded to power hierarchies, expectations and assumptions, is of importance when trying understand the ability of coaches to affect agency effectively in any given moment or situation (Cushion \& Jones, 2006; Jones, Armour \& Potrac, 2004; Purdy \& Jones, 2011).

The actions of coaches are consistent with contemporaries in education who, in navigating their employment spaces in times of turbulence and (perceived or potential) 'threats', undertook (career) identity work and adjusted their professional ideals in order to navigate their situations and ‘survive’ (Vähäsantanen \& Eteläpelto, 2009; Ketelaar et al., 2012; Eteläpelto et al., 2015). For teachers, there were instances when the contextual circumstances and relationships precipitated distinct, yet individualised, courses of action. Moreover, workers' capacity for active and/or passive agency at these junctures were closely linked to their sense of autonomy and their underlying ethical values that were being compromised by an unworkable environment (Ketelaar et al., 2012; Pyhalto et al., 2014). As referenced in the quotations above, these processes are evident in the coaches' acknowledgement of the realities of a limited contractual tenure and the implications this has on deciding to act or not to act on an immediate change in employment. Part of what informs their decision to act (or not to act) is related to historical and emotional connections to the game. 
Professional agency: Agents. One of the key components of professional agency is the inherent reliance on establishing and maintaining effective working relationships with others in the sporting community (who do not necessarily all exert the same level of influence or pressure as those within the immediate organisational context, or subscribe to the same ethical ideals and codes of conduct). The respective working relationships between the owners was in contradistinction to the interactions with agents. With regards to coaches' relationships with owners there was a more direct economic, political and managerial connection and hierarchy to the interaction which influenced (and potentially constrained) the coach's sense of autonomy, decision making capabilities and enactment of agency. In contrast, the relationship with agents was not imbued with the same significance (in terms of career control and economic security), and accordingly the coaches exhibited a greater sense of autonomy within the working relationship; a consequence of which, as the data attests, is the capacity for the coach to choose to work with an agent or not. Appreciating this difference is important in demonstrating the varied relational politics and contextual nuances within this particular industry, but also the value of drawing attention to the processes of professional agency which contour coach as a worker.

For example, the coaches noted the difficulty in obtaining a candid appraisal of a potential player from agents, "Everybody wants to make money, but big money. They want to hide [player's] habits, bad habits...If you ask about that, nobody will answer you honestly” (Coach B). In contrast to the scenario with the owner in which the coach's professional agency was restricted, in situations with the agents, coaches were able to exert their agency and undertake their own investigations of players. Additionally, the coaches had developed stronger relationships with some agents, who they trusted more than others, and referred to them when possible. "Now I have couple of people that I can call to get the right information” (Coach C). 
In addition to being aware of the agent's motives with regards to 'selling' players, coaches commented upon issues with the proliferation of agent's dubious practices. For example, the presence of tying/bundling in player negotiations. As Coach D commented, "Today there are cases when agents find a coach a job... and gives him a condition, you must take 7 or 8 players from my portfolio....” Here the coach's relationship with agents had a discernible impact on their working environment, the relationships with players and the club, and their sense of autonomy and control.

The interactions that coaches have with stakeholders in this space, as evidenced above with the concerns over agents, are quite complex and become increasingly more so the greater stakeholder's involvement, tiers within the community hierarchy, and/or higher the stakes may be. Rehearsing Mrozowicki et al. (2010), in their performances of agency coaches' decisions and conscious choices matter in terms of how they responded to, adjusted, and maneuvered themselves in the short term and over the course of their careers in light of agents' involvements. Coaches’ experiences here cohere with research within other employment and occupational settings examining the utility of relational networks (what others might consider social capital) in consolidating worker's sense of professional agency, by enabling individuals to exhibit greater confidence in decision making, providing further flexibility and choice when they decide to act/not act, and/or affording them pronounced security in uncertain times (Loury, 2006; Bentolila, Michelacci \& Suarez, 2010; Pellizzari, 2010; Faulconbridge \& Muzio, 2012).

\section{Conclusion}

Notwithstanding the global scope and sport-related labour, within the sociology of work diverse forms of employment within the sport industry have not been afforded much consideration. Nor, for that matter, has due consideration been given to the coaching profession within the context of work, occupational dynamics, labour relations and 
employment ethics. Thus, in this paper we sought to position coaches as workers within the sport sector. The spaces they inhabit and work they undertake makes the position of the professional sports coach a useful site in which to interrogate sport labour relations. Akin to other employment settings, for the coaches we interviewed, who work in the professional European basketball setting, their careers are characterised by organisational complexity, the influence of multiple stakeholders, varied hierarchical relationships, at times tenuous employment conditions, surveillance and control mechanism, and variable autonomy. Moreover, their daily occupations are further shaped by the specificities of the local contexts in which they operate. Such forces invariably impact upon their career identities and professional ideals, decision making capacities and necessity of negotiating moment of turbulence/uncertainty (consistent with examinations of other employment settings).

Although the industry space has, invariably, become more turbulent, managerial and uncertain, this has not necessarily precipitated a rise of disgruntled coaches, but rather a recognition of the increased difficulties of their work. The coaches we interviewed appeared to thrive off their inherent love of the game and its drama. So much so that the possibility of 'leaving' coaching to pursue another career, was not considered. This is unsurprising given it has played a predominant role throughout their lives (four were top level players). Their affectations for, and previous affiliations with, their sport are entwined within the conceptualisation of professional agency; or as the coaches may articulate, their ability 'to do good work' and/or 'work normally'. An appreciation of the historical connections to employment, or in this case a chosen career context, is useful in understanding workers' capacities to exert agency in any given situation. We identified that coaches' perceptions of other stakeholders (owner and agents in this case) come to bear on their conceptualisation of professional agency. 
As the data attests, an owner’s heavy-handed involvement with the coach’s work may have implications on their professional agency and overall job satisfaction, motivation, professional identity, sense of stability in the role and day-to-day working relationships. Here, the situation for coaches (and their ability to exert agency) is contingent and complicated by a number of factors that layer the coach's individual experiences and decisions. Some coaches demonstrated active professional agency. In particular, the interviewed coaches identified times when situations were unworkable with no sign of possible improvement as a result of organisational constraints. At these career junctures, some coaches renegotiated their professional ideals and adjusted. In contrast, coaches who chose not to renegotiate their professional ideals sought to protect their reputations by actively exerting their professional agency and put themselves in a more precarious employment position. For example, taking short(er) term contracts or leaving jobs prematurely. This was in contrast to the coaches' work with agents in which the political interference, power relations and economic consequences were less pronounced, enabling coaches to demonstrate more autonomy, and stronger professional agency (Loury, 2006; Bentolila et al., 2010; Suarez, 2010).

This paper has drawn attention to some of the issues, complexities and boundaries of coach's work. Our aim was not to portray coaches as resistant to the requirements of their positions, rather, to exemplify some of the employment realities of a small cohort of professional basketball coaches in Europe, and understand how their perceptions of other stakeholders' impact upon their individual circumstances, career expectations/objectives and professional agency. In keeping with current paucities within work and labour scholarship, we recognise the need to interrogate a broader array of professional sport settings and account for the diversities of experience inherent within sport work. The setting for this research provides $a$ space in which sport work and the machinations of the sport industry may 
be studied. Given the recent, and ongoing dramatic geo-political and economic shifts within the European context (vis-a-vis European Union relations and associated workers' rights and migratory issues, for example) (Galgóczi, Leschke \& Watt, 2016), scholarly settings such as this remain warranted and of value. 


\section{References}

Bentolila, S., Michelacci, C., \& Suarez, J. (2010). Social contacts and occupational choice. Economica, 77(305), 20-45.

Berntsen, L. (2016). Reworking labour practices: on the agency of unorganized mobile migrant construction workers. Work, Employment \& Society, 30(3), 472-488.

Chatzigianni, E. (2014). Pluralism and corporatism in sport interest representation. International Journal of Sport Policy and Politics, 6(1), 19-36.

Chesterfield, G., Potrac, P. \& Jones, R.L. (2010). ‘Studentship’ and ‘impression management': Coaches’ experiences of an advanced soccer coach education award. Sport, Education and Society, 15(3), 299-314.

Christensen, M.K. (2013). Outlining a typology of sports coaching careers: Paradigmatic trajectories and ideal career types among high performance sports coaches. Sports Coaching Review, 2(2), 98-113.

Collin, K., Paloniemi, S., \& Vähäsantanen, K. (2015). Multiple forms of professional agency for (non)crafting of work practices in a hospital organization. Nordic Journal of Working Life Studies, 5(3), 63-83.

Cooper, S. (2013). Some reflections on the romance and degradation of sports: Watching and metawatching in the changing transitional space of sport. Contemporary Psychoanalysis, 46(4), 510-522.

Cushion, C.J. \& Jones, R.L. (2006). Power, discourse and symbolic violence in professional youth soccer: The case of Albion F.C. Sociology of Sport Journal, 23(2), 142-161.

Emerson, R. M. (2001). Contemporary field research: Perspectives and formulations (2nd edition). Waveland Press: Long Grove, Illinois.

Engeström, Y., \& Sannino, A. (2010). Studies of expansive learning: Foundations, findings and future challenges. Educational Research Review, 5(1), 1-24. 
Engle, R. A., \& Faux, R.B. (2006). Towards productive disciplinary engagement of prospective teachers in educational psychology: Comparing two methods of case-based instruction. Teaching Educational Psychology, 1(2), 1-22.

Eteläpelto, A., Vähäsantanen, K., \& Hökkä, (2015), P. (2015). How do novice teachers in Finland perceive their professional agency? Teachers and Teaching: Theory and Practice 21(6), 660-680.

Eteläpelto, A., Vähäsantanen, K., Hökkä, P., \& Paloniemi, S. (2013). What is agency? Conceptualizing professional agency at work. Educational Research Review, 10, 4565.

EUAthletes (2015). EU Athletes common position paper. Retrieved from: http://www.euathletes.org/uploads/media/EUA COMMON POS BDef.pdf.

Faulconbridge, J., \& Muzio, D. (2012). Professions in a globalizing world: towards a transnational sociology of the professions. International Sociology, 27(1), 136-52.

Fevre, R. (2007). Employment insecurity and social theory: the power of nightmares. Work Employment \& Society, 21(3), 517-535.

Freebody, P. (2004). Hindsight and foresight: putting the four roles model of reading to work in the daily business of teaching. In A. Healy \& E. Honan (Eds.), Text next: new resources for literacy learning (pp. 3-17). NSW: Primary English Teaching Association.

Galgóczi, B., Leschke, J., \& Watt, A. (2016). EU labor migration in troubled: Skills mismatch, return and policy responses. New York: Routledge.

Gardiner, J., Stuart, M., Mackenzie, R., Forde, C., Greenwood, I., \& Perrett, R. (2009). Redundancy as a critical life event: moving on from the Welsh steel industry through career change. Work, Employment \& Society, 23(4), 727-745.

Glavin, P. (2013). The impact of job insecurity and job degradation on the sense of personal 
control. Work \& Occupations, 40(2), 115-142.

Goffman, E. (1969). Where the action is. London: Penguin Press.

Henry, I. (2013). Athlete development, athlete rights and athlete welfare: A European Union perspective. International Journal of the History of Sport, 30(4), 356-373.

Jones, R., Armour, K. \& Potrac, P. (2004). Sports Coaching Cultures: From practice to theory. London: Routledge.

Jones, R. L., \& Wallace, M. (2006). The coach as orchestrator. In R. L. Jones (Ed.), The sports coach as educator: Re-conceptualising sports coaching (pp. 51-64). London: Routledge.

Ketelaar, E., Beijaard, D., Boshuizen, H.P.A., \& Den Brok, P.J. (2012). Teachers' positioning towards an educational innovation in the light of ownership, sense-making and agency. Teaching and Teacher Education, 28, 273-282.

Lasky, S. (2005). A sociocultural approach to understanding teacher identity, agency and professional vulnerability in a context of secondary school reform. Teaching and Teacher Education, 21(8), 899-916.

Lavallee, D. (2006). Career awareness, career planning and career transition needs among sports coaches. Journal of Career Development, 33(1), 66-79.

Lipponen, L., \& Kumpulainen, K. (2011). Acting as accountable authors: Creating interactional spaces for agency work in teacher education. Teaching and Teacher Education, 27(5), 812-819.

Loury, L.D. (2006). Some contacts are more equal than others: Informal networks, job tenure, and wages. Journal of Labor Economics, 24(2), 299-318.

Madella, A. (2003). Methods for analysing sports employment in Europe. Managing Leisure, 8(2), 56-69.

Markovits, Y., Boer, D., \& van Dick, R. (2014). Economic crisis and the employee: The effects 
of economic crisis on employee job satisfaction, commitment, and self-regulation. European Management Journal, 32(3), 413-422.

Merriam, S.B. (2009). Qualitative research: a guide to design and implementation (2nd ed.). San Francisco: Jossey-Bass.

Miles, R. (2015). Complexity, representation and practice: Case study as method and methodology. Issues in Educational Research, 25(2), 309-318.

Mills, J. \& Denison, J. (2016). How power moves: A Foucauldian analysis of (in)effective coaching. International Review for the Sociology of Sport, 1-17.

Morrow, S. \& Howieson, B. (2014). The new business of football: A study of current and aspirant football club managers. Journal of Sport Management, 28(5), 515-528.

Mrozowicki, A., Pulignano, V., \& Van Hootegem, G. (2010), Worker agency and trade union renewal: the case of Poland. Work, Employment \& Society, 24(2), 221-240.

Parrish, R. (2015). The European social dialogue: A new mode of governance for European football? In A. Duval \& B. Van Rompuy (Eds.), 20 Years After: The Legacy of Bosman (pp. 26-52). New York: Springer,

Patton, M. (1990). Qualitative evaluation and research methods (pp. 169-186). Beverly Hills, CA: Sage.

Pellizzari, M. (2010). Do friends and relatives really help in getting a good job? Industrial \& Labor Relations Review, 63(3), 494-510.

Potrac, P., \& Jones, R. (2009). Micropolitical workings in semi-professional football. Sociology of Sport Journal, 26, 557-57.

Priestley. M., Edwards. R., Priestley. A., \& Miller, K. (2012). Teacher agency in curriculum making: Agents of change and spaces for manoeuvre. Curriculum Inquiry, 42, 191214.

Purdy, L.G. \& Jones, R. (2011). Choppy waters: Elite rowers’ perceptions of coaching. 
Sociology of Sport Journal, 28(3), 329-346.

Purdy, L.G. \& Potrac, P. (2014). Am I just not good enough? The creation, development and questioning of a high performance coaching identity. Sport, Education and Society.

Pyhalto, K., Pietarinen, J., \& Soini, T. (2014). Comprehensive school teachers’ professional agency in large-scale educational change. Journal of Educational Change, 15, 303325.

Rainio, A.P. (2008). From resistance to involvement: examining agency and control in a playworld activity. Mind, Culture and Activity, 15(2), 115-140.

Rigozzi, A. (2010). Challenging awards of the Court of Arbitration for sport. Journal of International Dispute Settlement, 1(1), 217-265.

Roderick, M. (2014). From identification to dis-identification: case studies of job loss in professional football. Qualitative Research in Sport, Exercise and Health, 6(2), 143160.

Roderick, M. (2013). From identification to dis-identification: case studies of job loss in professional football. Qualitative Research in Sport, Exercise and Health, 1.

Roderick, M. (2006). The work of professional football: A labour of love? London: Routledge.

Ronglan, L.T., \& Aggerholm, K. (2014). 'Humour helps’: Elite sports coaching as a balancing act. Sports Coaching Review, 3, 1, 33-45

Santos, S., Jones, R.L., \& Mesquita, I. (2013). Do coaches orchestrate? The working practices of elite Portuguese coaches. Research Quarterly for Exercise and Sport, 84(2), 263272.

Schulenkorf, N., \& Frawley, S. (2016). Critical issues in global sport management. London: Routledge.

Strachan, J. (2013). Romanticism and sport. Romanticism, 19(3), 233-245. 
Stake, R. (1995). The art of case study research. Thousand Oaks, CA: Sage.

Stronach, I., Corbin, B., McNamara, O., Stark, S., \& Warne, T. (2002). Towards an uncertain politics of professionalism: teacher and nurse identities in flux. Journal of Education Policy, 17, 109-138.

Syndex. (2013). An analysis of the working conditions of professional sports players.

Financially supported by the European Commission.

Thomas, G. (2010). Doing case study: Abduction not induction, phronesis not theory. Qualitative Inquiry, 16(7), 575-582.

Thompson, A., Potrac, P. \& Jones, R. (2015). 'I found out the hard way: micro-political workings in professional football. Sport, Education and Society, 20(8).

Tracy, S. (2013). Qualitative research methods: Collecting evidence, crafting analysis, communicating impact. Oxford: John Wiley and Sons Ltd.

Vähäsantanen, K. (2015). Professional agency in the stream of change. Teaching and Teacher Education, 47, 1-12.

Vähäsantanen, K., \& Eteläpelto, A. (2015). Professional agency, identity, and emotions while leaving one’s work organization. Professions \& Professionalism, 5(3).

Vähäsantanen, K., \& Eteläpelto, A. (2009). Vocational teachers in the face of a major educational reform: Individual ways of negotiating professional identities. Journal of Education and Work, 22(1), 15-33.

Wallace, M. (1988). Labor market structure and salary determination among professional basketball players. Work \& Occupations, 15(3), 294-312.

Willis, P.E. (1977). Learning to labor: How working class kids get working class jobs. New York: Columbia University Press. 